DOI 10.22460/jpmi.v1i3.453-458

\title{
ANALISIS KEMAMPUAN HIGH ORDER THINKING (HOT) SISWA SMP NEGERI DI KOTA CIMAHI
}

\author{
Yuni Hajar ${ }^{1}$, Ridwan Yanwar ${ }^{2}$, Muhamad Agus Jalaludin ${ }^{3}$, Naskia Achmad ${ }^{4}$, Gita \\ Safira Indriani ${ }^{5}$, Wahyu Hidayat ${ }^{6}$, Euis Eti Rohaeti $^{7}$ \\ 1,2,3,4,5,6,7 IKIP Siliwangi, Jl. Terusan Jenderal Sudirman, Cimahi, Jawa Barat, Indonesia \\ 1yuni28h@gmail.com, ${ }^{2}$ ridwan.yanwar11@gmail.com, ${ }^{3}$ muhamadagusj17@gmail.com, \\ nnaskiaa27@gmail.com, ${ }^{4}$ gitasafira687@gmail.com, ${ }^{6}$ wahyu@ikipsiliwangi.ac.id, \\ 7e2rht@ikipsiliwangi.ac.id
}

Diterima: 10 Maret 2018; Disetujui: 28 Mei 2018

\begin{abstract}
High order thinking skill is an important skill that student must have, especially in mathematics education. In the process of solving problems, students are required to be able to think fundamental and creative. The purpose of this research is to analyze the comparison of high order thinking ability of students in SMPN Cimahi based on school classification. The research method used is experimental with the design of two class and post-test only. the sample taken in this research is the students of class VII SMPN in Cimahi with high classification and moderate classification. The result of this research is there's still a very significant difference in high order thinking the skill of junior high school student in Cimahi city. SMPN with high classification has good high order thinking skills than SMPN with moderate classification. This is due to the following factors, (a) the students have different bits of intelligence; (b) the way students face difficulties (problems) that varies depending on how the students' everyday learning process; (c) the classification of schools have an effect on student's high order thinking skill.
\end{abstract}

Keywords: High Order Thinking Skill

\begin{abstract}
Abstrak
Kemampuan tingkat tinggi merupakan kemampuan yang penting untuk dimiliki oleh seorang siswa, terutama dalam bidang pelajaran matematika. Dalam proses menyelesaikan masalah siswa dituntut untuk dapat berpikir mendasar serta kreatif. Tujuan dari penelitian ini adalah untuk menganalisis perbandingan kemampuan high order thinking siswa SMPN di Cimahi berdasarkan klasifikasi sekolah. Metode penelitian yang digunakan adalah metode eksperimen dengan disain dua kelas dan hanya soal postes. sampel yang diambil dalam penelitian ini adalah siswa kelas VII SMPN di Cimahi dengan klasifikasi tinggi dan klasifikasi sedang. Hasil dari penelitian ini adalah kemampuan high order thinking siswa SMP di kota Cimahi ternyata masih terdapat perbedaan yang sangat signifikan. Siswa SMPN dengan klasifikasi tinggi memiliki kemampuan high order thinking yang lebih baik daripada SMPN dengan kalisifikasi sedang. Hal tersebut disebabkan karena faktor-faktor berikut, (a) siswa memiliki tingkatan kecerdasan yang berbeda-beda; (b) cara siswa menghadapi kesulitan (soal) yang berbeda-beda tergantung bagaimana keseharian siswa melakukan pembelajaran; (c) klasifikasi sekolah memiliki pengaruh terhadap kemampuan high order thinking siswa.
\end{abstract}

Kata Kunci: Kemampuan Berpikir Tingkat Tinggi

How to cite: Hajar, Y., Yanwar, R., Jalaludin, M. A., Achmad, N., Indriani, G. S., Hidayat, W., \& Rohaeti, E. E. (2018). Analisis Kemampuan High Order Thinking (HOT) Siswa SMP Negeri di Kota Cimahi. JPMI - Jurnal Pembelajaran Matematika Inovatif, 1 (3), 453-458. 


\section{PENDAHULUAN}

Menurut Widiawati \& Joyoatmojo (2018) kemampuan berpikir tingkat tinggi (high order thingking skill) adalah salah satu kemampuan matematis seseorang yang menghubungkan pengetahuan dan pengalamannya untuk dapat memecahkan suatu permasalahan secara kreatif dan kritis secara mendalam.

Sementara menurut Rofiah, Aminah \& Ekawati (2013) kemampuan high order thinking adalah kemampuan yang penting untuk dimiliki oleh seorang siswa, terutama dalam bidang pelajaran matematika. Dalam proses menyelesaikan masalah siswa dituntut untuk dapat berpikir mendasar serta kreatif.

Menurut Krathwohl (Komariah, 2016), kemampuan high order thinking memiliki indikator sebagai berikut, (a) Menganalisis (Analyzing), peserta didik mampu menguraikan atau merinci suatu permasalahan dalam bentuk soal menjadi suatu bagian yang lebih kecil dari permasalahan tersebut dan siswa pun mampu mengerti hubungan atau keterkaitan antara bagian-bagian tersebut; (b) Mengevaluasi (Evaluating), peserta didik mampu membuat suatu pertimbangan mengenai suatu kondisi, metode ataupun ide; (c) Mengkreasi (Creating), peserta didik mampu mensintesis atau membuat pengetahuan atau informasi menjadi pengetahuan yang baru.

Kemampuan high order thinking merupakan salah satu kemampuan penting yang perlu dimiliki oleh seorang siswa, terutama dalam bidang pelajaran matematika. Dalam proses menyelesaikan masalah siswa dituntut untuk dapat berpikir mendasar (kritis) serta kreatif. Akan tetapi fakta dilapangan kemampuan tingkat tinggi masih sangatlah rendah dikalangan siswa sekolah menengah, hal ini sejalan dengan penelitian yang dilakukan oleh Rosmaiyadi (2017). Dalam penelitiannya terlihat bahwa kemampuan berpikir kritis siswa masih termasuk rendah, ini terlihat pada saat siswa SMP Negeri 19 Singkawang diberikan soal-soal non rutin pada materi geometri sebagian besar dari siswa mengalami kesulitan dalam memecahkan permasalahan dalam soal dan menjawabnya. Selain itu dalam menjawab persoalan tersebut siswa hanya mampu menuliskan apa saja yang diketahui tanpa menyertakan cara penyelesaiannya, mereka cenderung menyelesaikannya dengan konsep dan cara sesuai dengan apa yang diterimanya dari guru di sekolah. Sejalan dengan itu Noddings (2004) menyatakan bahwa siswa dengan kemampuan kritis yang rendah akan sering melewatkan atau tidak mengerjakannya pada saat diberi soal-soal yang memuat berpikir kritis.

Menurut Supardi (Hidayat dan Sariningsih, 2018) keberhasilan siswa dalam proses pembelajaran tergantung pada bagaimana cara siswa mengatasi kesulitan yang ada. Cara mengatasi kesulitan setiap orang berbeda-beda. Demikian pula, tingkat kecerdasan seseorang relative berbeda. Melihat masih kurangnya kemampuan high order thinking dan berbedanya tingkat kecerdasan siswa, akhirnya penulis memutuskan untuk menganalisis kemampuan hihg order thinking siswa SMP Negeri di kota Cimahi berdasarkan tingkatan klasifikasi sekolah. Berdasarkan rumusan masalah tersebut, artikel ini bertujuan untuk menganalisis perbandingan kemampuan high order thinking siswa SMP Negeri di kota Cimahi berdasarkan klasifikasi sekolah.

\section{METODE}

Metode penelitian yang digunakkan dalam penelitian ini adalah metode eksperimen dengan disain dua kelas kontrol dan hanya soal postes. Berdasarkan klasifikasi tingkatan SMP Negeri di kota Cimahi, sampel yang dipilih adalah siswa kelas VII SMP Negeri di Cimahi dengan 
klasifikasi sekolah tinggi dan siswa kelas VII SMP Negeri di Cimahi dengan klasifikasi sekolah sedang.

Tes kemampuan high order thinking dilaksanakan pada tanggal 4 Mei di SMP Negeri yang memiliki klasifikasi sedang dan tanggal 7 Mei di SMP Negeri yang memiliki klasifikasi tinggi. Sampel dalam penelitian ini berjumlah 66 dengan 32 orang siswa di SMP Negeri yang memiliki klasifikasi tinggi dan 34 orang siswa di SMP Negeri yang memiliki klasifikasi sedang.

Instrumen dalam penelitian ini merupakan tes kemampuan high order thinking dengan contoh soal seperti berikut :

3. Kamar tidur Pak Tono berukuran 3 meter $\times 2,4$ meter. Pak Tono ingin kamarnya dipasangi ubin. Ada dua pilihan ubin dengan informasi harga disajikan dalam tabel berikut:

\begin{tabular}{|c|c|}
\hline Ukuran ubin & Harga/ubin \\
\hline $20 \mathrm{~cm} \times 20 \mathrm{~cm}$ & $\mathrm{Rp} 1.700,00$ \\
\hline $30 \mathrm{~cm} \times 30 \mathrm{~cm}$ & $\mathrm{Rp} 3.600,00$ \\
\hline
\end{tabular}

Berdasarkan informasi pada tabel, ukuran ubin manakah yang sebaiknya dipilih

Pak Tono agar agar biaya yang dibelanjakan lebih sedikit?

Gambar 1. Contoh Instrumen tes kemampuan high order thinking

\section{HASIL DAN PEMBAHASAN}

\section{Hasil}

Berdasarkan hasil tes kemampuan high order thinking di SMP Negeri yang memiliki klasifikasi tinggi dan SMP Negeri yang memiliki klasifikasi sedang, berikut rincian nilai yang disajikan dalam Tabel 1.

Tabel 1. Nilai postes SMP dengan klasifikasi tinggi dan SMP dengan klasifikasi sedang

\begin{tabular}{lcccc}
\hline \multicolumn{1}{c}{ Level Sekolah } & Min & Max & Rata-rata & SD \\
\hline SMP klasifikasi tinggi & 0 & 16 & 93.438 & 461.141 \\
SMP klasifikasi sedang & 0 & 7 & 24.706 & 237.710 \\
\hline
\end{tabular}

\section{Pembahasan}

Analisis data dalam penelitian ini menggunakan bantuan olah data statistik SPSS, berikut hasil olah data SMP Negeri yang memiliki klasifikasi tinggi dan sedang. 
Tabel 2. Deskripsi Statistik HOT

\begin{tabular}{ccccc}
\hline Level Sekolah & N & Mean & $\begin{array}{c}\text { Std. } \\
\text { Deviation }\end{array}$ & $\begin{array}{c}\text { Std. Error } \\
\text { Mean }\end{array}$ \\
\hline Tinggi & 32 & 9.3438 & 4.61141 & 0.81519 \\
Sedang & 34 & 2.4706 & 2.37710 & 0.40767 \\
\hline
\end{tabular}

Berdasarkan hasil olah data SPSS pada tabel 2, terlihat bahwa siswa di SMP Negeri yang memiliki klasifikasi tinggi berjumlah 32 orang dan siswa di SMP Negeri yang memiliki klasifikasi sedang berjumlah 34 orang. Rata-rata nilai tes kemampuan high order thinking untuk SMP Negeri yang memiliki klasifikasi tinggi adalah 9,3438. Sementara rata-rata nilai tes kemampuan high order thinking untuk SMP Negeri yang memiliki klasifikasi sedang adalah 2,4706. Terdapat perbedaan yang signinfikan antara nilai rata-rata SMP Negeri yang memiliki klasifikasi tinggi dengan nilai rata-rata SMP Negeri yang memiliki klasifikasi sedang. Dapat ditarik kesimpulan sementara bahwa kemampuan high order thinking siswa SMP Negeri yang memiliki klasifikasi tinggi lebih baik daripada siswa SMP Negeri yang memiliki klasifikasi sedang. Untuk membuktikan apakah kesimpulan sementara itu benar atau salah, maka akan dilakukan uji hipotesis, yaitu melakukan uji t untuk dua sampel yang saling lepas (Independent t-test).

Tabel 3. Uji Perbedaan Rerata

\begin{tabular}{|c|c|c|c|c|c|c|c|c|c|c|}
\hline & & \multicolumn{4}{|c|}{$\begin{array}{c}\text { Levene's Test } \\
\text { for Equality } \\
\text { of Variances }\end{array}$} & \multicolumn{5}{|c|}{ t-test for Equality of Means } \\
\hline & & \multirow[b]{2}{*}{$\mathbf{F}$} & \multirow[b]{2}{*}{ Sig. } & \multirow[b]{2}{*}{$\mathbf{t}$} & \multirow[b]{2}{*}{ df } & \multirow{2}{*}{$\begin{array}{l}\text { Sig. } \\
(2- \\
\text { tailed })\end{array}$} & \multirow{2}{*}{$\begin{array}{c}\text { Mean } \\
\text { Difference }\end{array}$} & \multirow{2}{*}{$\begin{array}{l}\text { Std. Error } \\
\text { Difference }\end{array}$} & \multicolumn{2}{|c|}{$\begin{array}{l}\text { 95\% Confidence } \\
\text { Interval of the } \\
\text { Difference }\end{array}$} \\
\hline & & & & & & & & & Lower & Upper \\
\hline \multirow[t]{2}{*}{ HOT } & $\begin{array}{l}\text { Equal } \\
\text { variances } \\
\text { assumed }\end{array}$ & 11.661 & 0.001 & 7.677 & 64 & 0.000 & 6.87316 & 0.89531 & 5.08458 & 8.66175 \\
\hline & $\begin{array}{l}\text { Equal } \\
\text { variances not } \\
\text { assumed }\end{array}$ & & & 7.541 & 45.756 & 0.000 & 6.87316 & 0.91144 & 5.03826 & 8.70807 \\
\hline
\end{tabular}

Berdasarkan analisis uji t pada Tabel 3 dapat terlihat bahwa nilai signifikansinya adalah 0,000, dimana itu berarti lebih kecil dari $\alpha=0,05$ dan nilai $\mathrm{t}=7,677$ lebih besar dari $\mathrm{t}$ kritis yaitu $\mathrm{t}_{(0,95,64)}=1,669$, maka Ho ditolak. Artinya kemampuan high order thinking siswa SMP Negeri yang memiliki klasifikasi tinggi lebih baik daripada siswa SMP Negeri yang memiliki klasifikasi sedang.

Dari kesimpulan hasil uji t tersebut dapat disimpulkan bahwa kemampuan high order thinking siswa SMP Negeri di kota Cimahi ternyata masih terdapat perbedaan yang sangat signifikan. Siswa SMP Negeri dengan klasifikasi tinggi memiliki kemampuan high order thinking yang lebih baik daripada SMP Negeri dengan klasifikasi sedang. 
Beberapa faktor penyebab siswa memiliki kemampuan high order thinking yang berbedabeda, yaitu, (a) siswa memiliki tingkatan kecerdasan yang berbeda-beda. (b) cara siswa menghadapi kesulitan (soal) yang berbeda-beda tergantung bagaimana keseharian siswa melakukan pembelajaran. (c) klasifikasi sekolah memiliki pengaruh terhadap kemampuan high order thinking siswa.

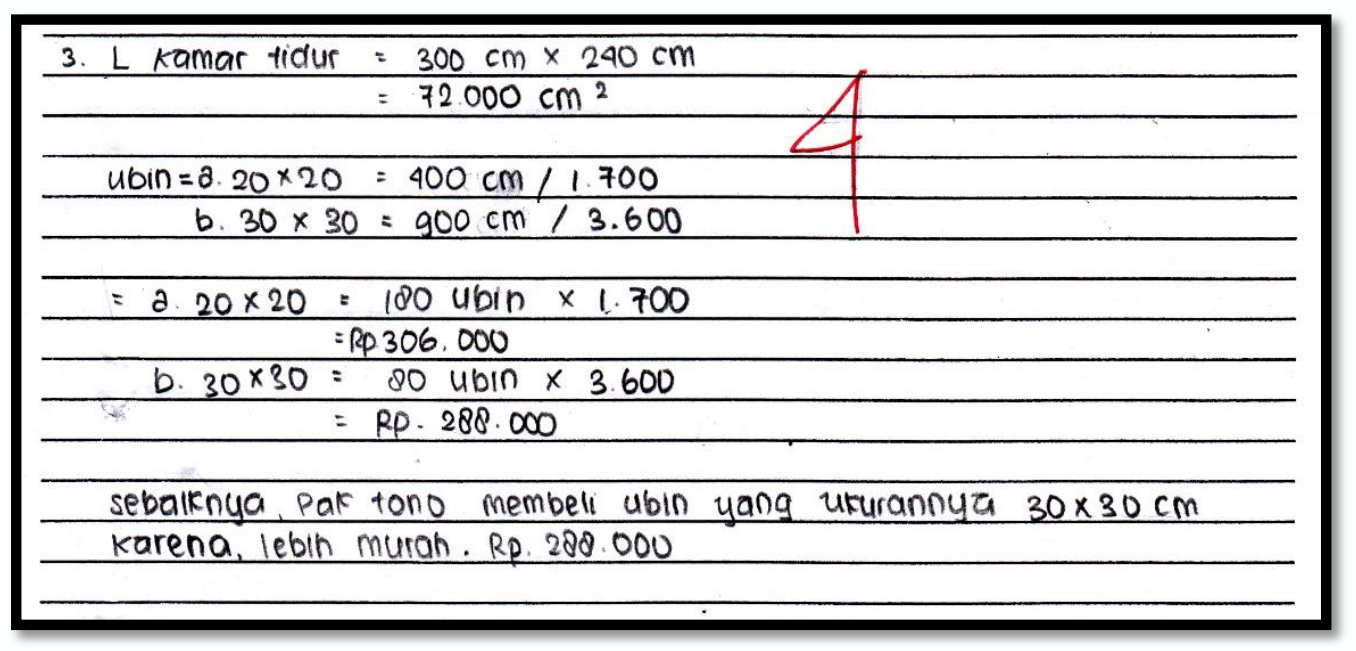

Gambar 2. Jawaban siswa dengan klasifikasi sekolah tinggi

Terlihat dalam jawaban siswa di SMP Negeri yang memiliki klasifikasi tinggi, siswa tersebut mampu menjawab soal tes tersebut dengan baik. Dia melakukan semua tahapan secara rinci. Dimulai dari mencari keseluruhan luas kamar tidur, mencari kemungkinan luas ubin pada ukuran tertentu, hingga perbandingan harga dari luas ubin yang dicari sebelumnya. Walaupun dia tidak memunculkan tentang perbandingan seniai, tapi dia sudah tau apa yang harus dilakukan dengan caranya sendiri. Ini menandakan bahwa siswa tersebut memiliki logika yang baik dan sudah mampu mengevaluasi cara memilih ukuran ubin agar biaya yang dibelanjakan sedikit. Mengevaluasi ini ada dalam indikator kemampuan high order thinking. Karena siswa sudah mampu mengevaluasi, maka siswa tersebut memiliki kemampuan high order thinking yang baik.

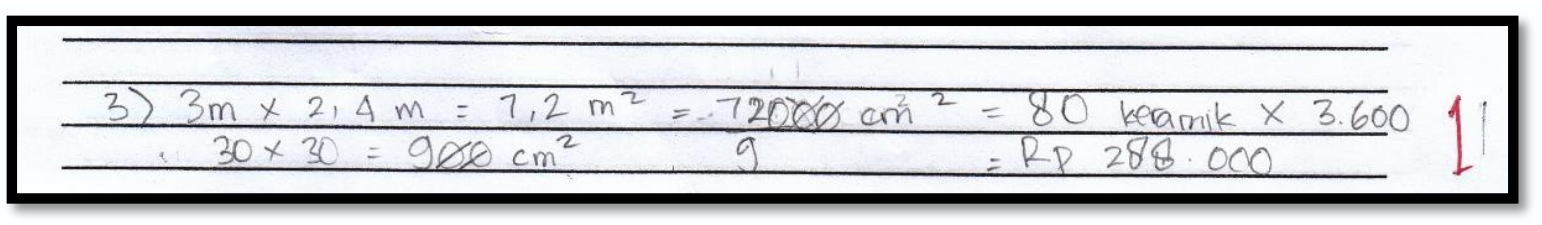

Gambar 3. Jawaban siswa dengan klasifikasi sekolah sedang

Berdasarkan jawaban siswa di SMP Negeri yang memiliki klasifikasi sedang terlihat bahwa siswa tersebut tidak mampu menganalisis soal secara baik. Terlihat dari bagaimana siswa yang hanya melakukan satu pengerjaan yaitu terhadap luas ubin $30 x 30$. Walaupun jawaban benar namun jika hanya mengerjakan separuh seperti itu, maka kemungkinan untuk menjawab salah adalah 50\%. Seharusnya siswa mengevaluasi cara memilih ukuran ubin agar biaya yang dibelanjakan sedikit, namun siswa tidak melakukannya. Ini menandakan bahwa siswa belum mampu mengevaluasi jawaban dengan baik, maka kemampuan high order thinking-nya pun masih kurang. 


\section{KESIMPULAN}

Berdasarkan hasil dan pembahasan dalam penelitian ini, maka dapat disimpulkan bahwa, (1) kemampuan high order thinking di kota Cimahi masing belum merata. Masih terdapat perbedaan yang signifikan antara kemampuan siswa di SMP Negeri dengan klisfikasi tinggi dengan siswa di SMP Negeri dengan klasifikasi sedang. Kemampuan high order thinking siswa di SMP Negeri dengan klasifikasi tinggi lebih baik dari pada siswa di SMP Negeri yang memiliki klasifikasi sedang; (2) Beberapa faktor penyebab siswa memiliki kemampuan high order thinking yang berbeda-beda, yaitu; (a) siswa memiliki tingkatan kecerdasan yang berbeda-beda; (b) cara siswa menghadapi kesulitan (soal) yang berbeda-beda tergantung bagaimana keseharian siswa melakukan pembelajaran; (c) klasifikasi sekolah memiliki pengaruh terhadap kemampuan high order thinking siswa.

\section{DAFTAR PUSTAKA}

Hidayat, W., \& Sariningsih, R. (2018). Kemampuan Pemecahan Masalah Matematis dan Adversity Quotient Siswa SMP Melalui Pembelajaran Open Ended. JNPM (Jurnal Nasional Pendidikan Matematika), 2(1), 109-118.

Komariah, S. (2016). Perbandingan Peningkatan Kemampuan Berpikir Matematis Tingkat Tinggi Siswa SMP antara yang Memperoleh Pembelajaran Model Problem-based Learning dan Discovery Learning. Skripsi. Universitas Pendidikan Indonesia. Tidak Diterbitkan.

Noddings, N. (2004) .Developing Critical-Thinking: War, Critical-Thinking, and SelfUnderstanding. Phi Delta Kappan, 85(7), 489-495.

Rofiah, E., Aminah, N. S., \& Ekawati, E. Y. (2013). Penyusunan Instrumen tes kemampuan berpikir tingkat tinggi fisika pada siswa SMP. Jurnal Pendidikan Fisika, 1(2).

Rosmaiyadi (2017).Analisis Kemmampuan Berpikir Kritis Matematis Siswa dalam Learning Cycle 7E Berdasarkan Gaya Belajar.Aksioma, 6(1), 12-19.

Widiawati, L., \& Joyoatmojo, S. (2018). Higher Order Thinking Skills Pada Pembelajaran Abad 21 (Pre Research). JOURNAL PROCEEDING, 4(1). 